Institute of $\mathbf{F}_{\text {ood and }} \mathbf{A}$ gricultural $\mathbf{S}_{\text {ciences }}$

\title{
Wasp Parasitoid Cotesia marginiventris (Cresson) (Insecta: Hymenoptera: Braconidae) ${ }^{1}$
}

Andrei Sourakov and Everett Mitchell ${ }^{2}$

\section{Distribution}

This species was originally described from Cuba and is native to the West Indies. It also occurs in the United States: Delaware south to Florida, west to Indiana, Kansas and Texas, Wisconsin, Arizona, California, Hawaii. It is also present in Mexico and South America.

\section{Description}

\section{Egg}

Oval, three times longer than wide, with a small projection. It is clear and shiny, like a piece of glass. Size increases after the egg is laid. Larva hatches two days after oviposition by the adult.

\section{Larva}

When dissected from the host, the Cotesia larvae are soft-skinned and bear a "bubble" - a caudal vesicle - in the posterior region. If not submerged in water, the larva dries out shortly after being dissected. Larvae are located in the host's posterior end. The first instar larvae are only $0.06 \mathrm{~mm}$ long, while mature (third instar) larvae are $5.5 \mathrm{~mm}$ long. When they emerge from the host, they are much more rugged and immediately begin spinning a tight silky cocoon.
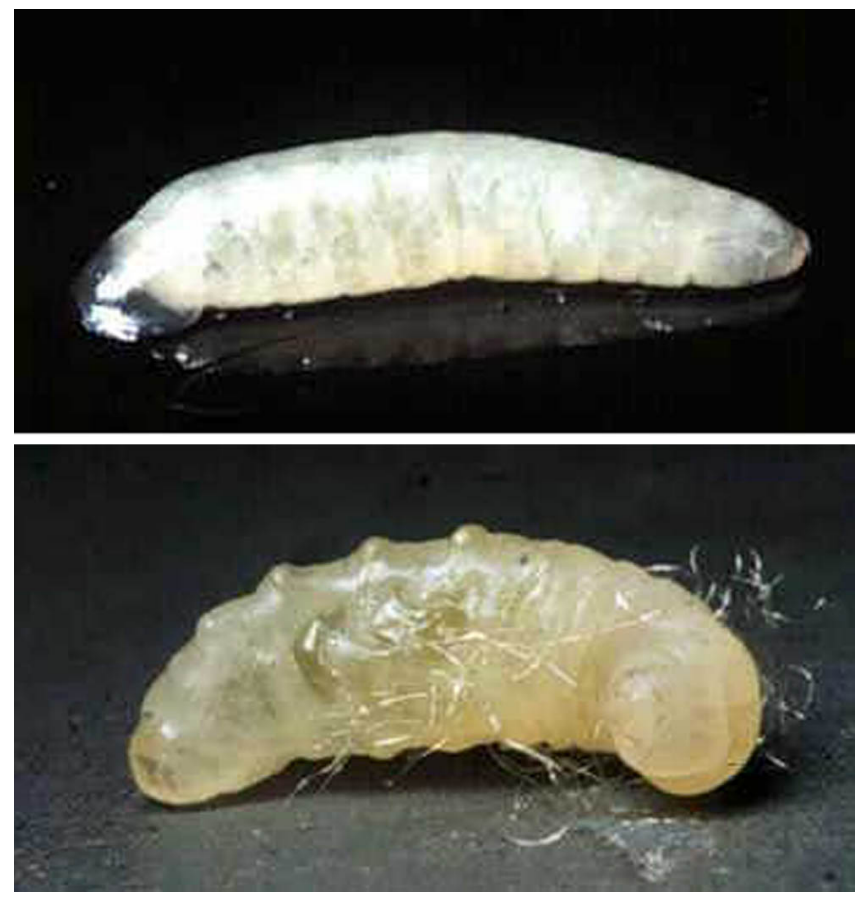

Figure 1. Early (top) and late (bottom) larval stages of Cotesia marginiventris (Cresson), a wasp parasitoid. Credits: Andrei Sourakov, USDA

1. This document is EENY-123, one of a series of Featured Creatures from the Entomology and Nematology Department, Florida Cooperative Extension Service, Institute of Food and Agricultural Sciences, University of Florida. Published: March 2000. This document is also available on Featured Creatures Website at http://creatures.ifas.ufl.edu. Please visit the EDIS Website at http://edis.ifas.ufl.edu. Additional information on these organisms, including many color photographs, is available at the Entomology and Nematology Department website at http://entnemdept.ifas.ufl.edu/.

2. Andrei Sourakov and Everett Mitchell, USDA, Gainesville, FL.

The Institute of Food and Agricultural Sciences is an equal opportunity/affirmative action employer authorized to provide research, educational information and other services only to individuals and institutions that function without regard to race, color, sex, age, handicap, or national origin. For information on obtaining other extension publications, contact your county Cooperative Extension Service office. Florida Cooperative Extension Service/Institute of Food and Agricultural Sciences/University of Florida/Christine Taylor Waddill, Dean. 


\section{Pupa}

The cocoon is white, tight and $4 \mathrm{~mm}$ long.

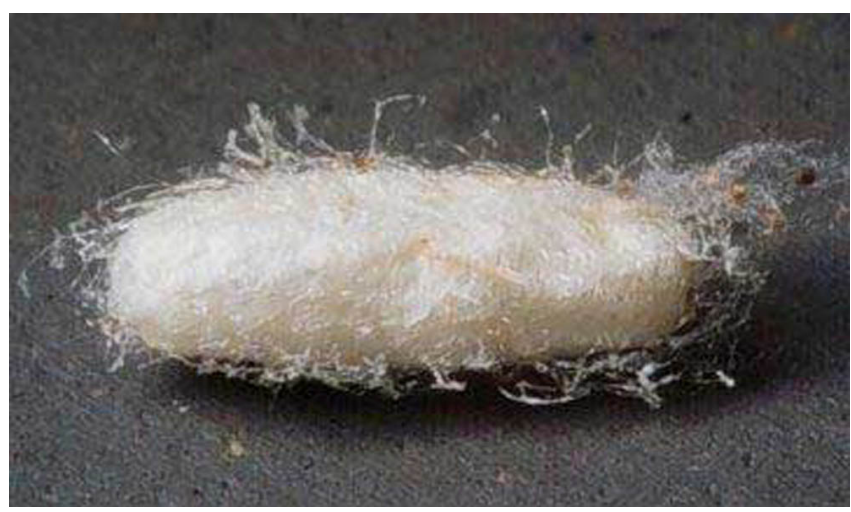

Figure 2. Cocoon of Cotesia marginiventris (Cresson), a wasp parasitoid. Credits: Andrei Sourakov, USDA

\section{Adult}

\section{C. marginiventris is a small insect}

(approximately $3 \mathrm{~mm}$ in length). Females bear short ovipositors and parasitize only young larvae or even eggs. In the laboratory, $C$. marginiventris lives more than a week, but it is most effective as a parasitoid between two and four days of age.



Figure 3. Adult male of Cotesia marginiventris (Cresson), a wasp parasitoid. Credits: Andrei Sourakov, USDA

\section{Life Cycle}

Cotesia marginiventris is a general parasitoid of noctuid pests. In Florida, it is abundant throughout the summer, but its populations decline from October

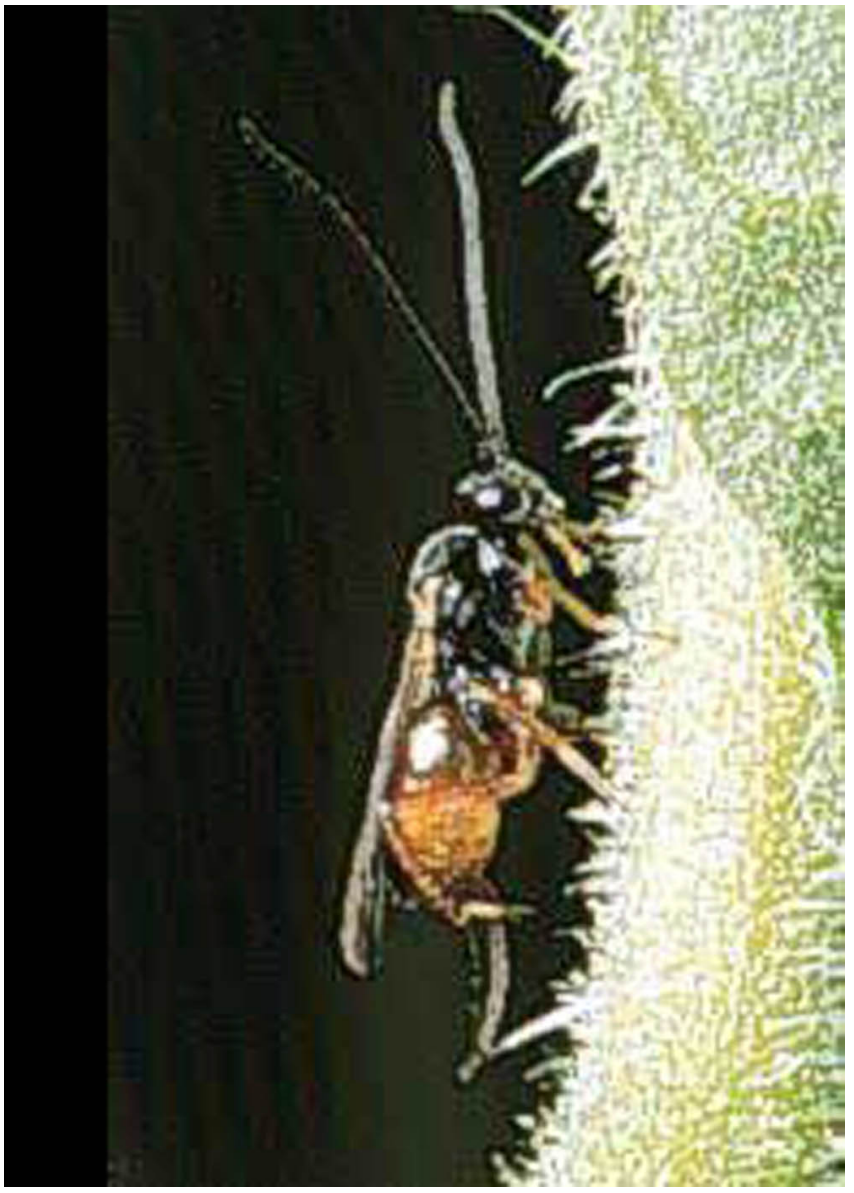

Figure 4. Adult female of Cotesia marginiventris (Cresson), a wasp parasitoid. Credits: Andrei Sourakov, USDA

Andrei Sourakov, USDA

to April. At 25 degrees $\mathrm{C}$ it develops in 13 days from egg to adult.

\section{Hosts}

C. marginiventris is a general parasitoid of noctuid moths. It attacks mostly very young larvae (first to second instar). A single egg is usually laid in each host, and the cocoon hatches in seven to10 days. The host, which feeds little throughout its life, dies shortly after the parasitoid emerges. After the mature parasitoid exits the host larvae, they die within a day. The exit hole in the side of the larva is only a superficial sign of the actual damage that occurred to the host. Practically all organs inside were consumed by the parasitoid. 
C. marginiventris is a parasite of Agrotis ipsilon (Hufn.), the black cutworm; Anagrapha falcifera (Kirby), the celery looper; Autographa precationis (Gn.); Autoplusia egena (Guen.), the bean leafskeletonizer; Helicoverpa zea (Boddie), the bollworm (also called the corn earworm or tomato fruitworm); Heliothis virescens (F.), the tobacco budworm; Hymenia perspectalis (Hbn.), the spotted beet webworm; $H$. recurvalis (F.); Leucania latiuscula H.-S.; L. multisulca Wlkr.; Peridroma saucia (Hbn.), the variegated cutworm; Plathypena scabra (F.); Pseudaletia unipuncta (Haw.), the armyworm; Pseudoplusia includens (Wlkr.), the soybean looper; Scotorythra caryopsis Meyr.; Spodoptera eridania (Cram.), the southern armyworm, S. exigua (Hbn.), the beet armyworm; $S$. frugiperda (Smith), the fall armyworm; $S$. ornithogalli (Guen.); S. praefica (Grote); and Trichoplusia $\mathrm{ni}$ (Hbn.), the cabbage looper.

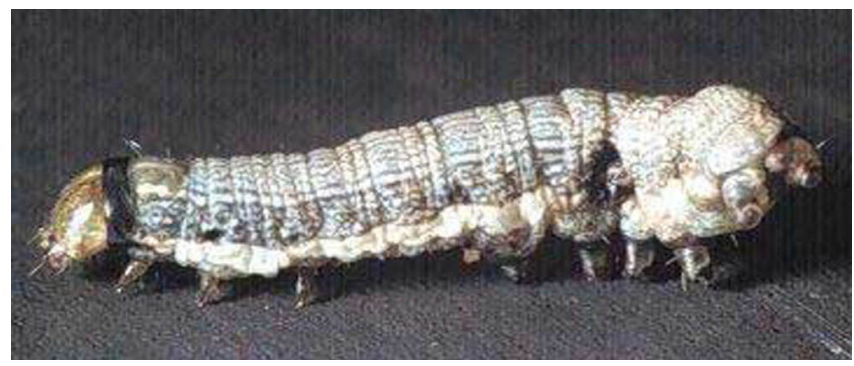

Figure 5. Exit hole made by a larva of Cotesia marginiventris (Cresson), a wasp parasitoid, in a beet armyworm, Spodoptera exigua (Hbn.). Credits: Andrei Sourakov, USDA

\section{Importance}

Considered for biological control of noctuid pests of vegetable crops, such as beet armyworm, cabbage looper, etc.

\section{Selected References}

Boling, J. C. and H. N. Pitre. 1970. Life history of Apanteles marginiventris with description of immature stages. J. of Kansas Entomol. Soc. 43: 465-470.

Jalali S. K., S. P. Singh, C. R. Ballal, and P. Kumar. 1990. Response of Cotesia marginiventris (Cresson) (Hymenoptera: Braconidae) to low temperature in relation to its biotic potential. Entomon 15: 217-220.

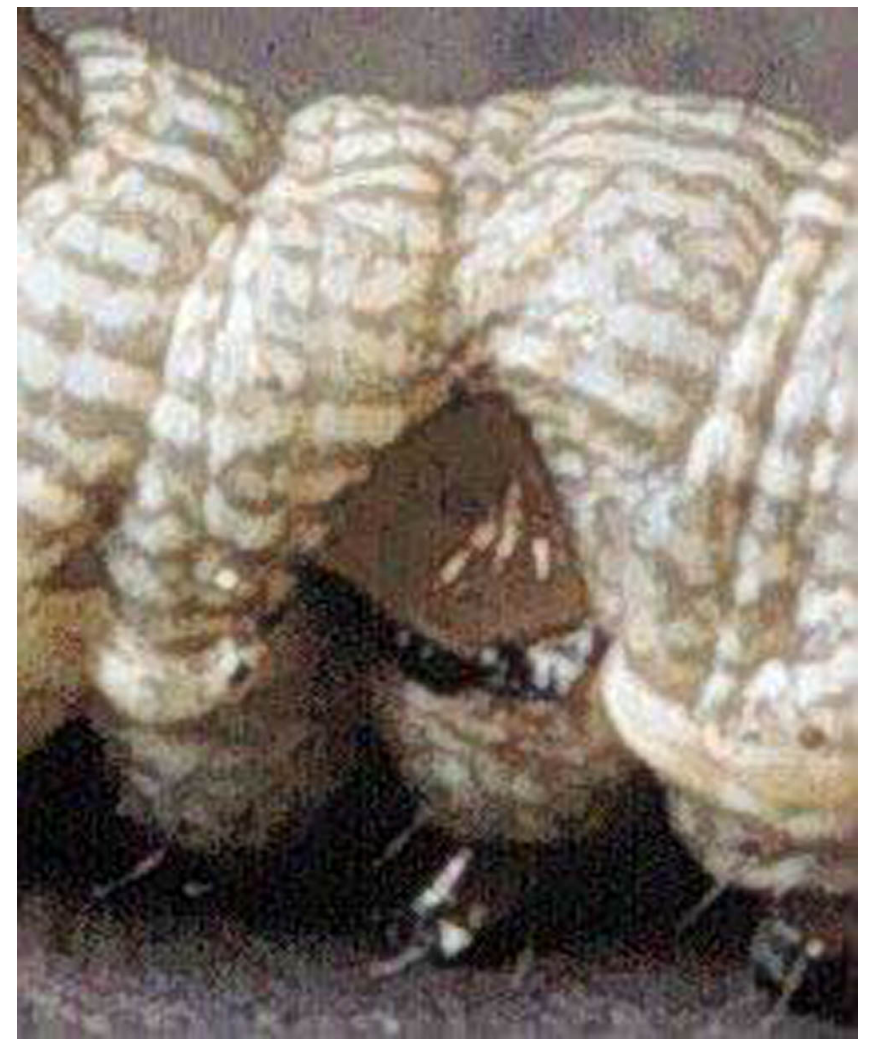

Figure 6. Closeup of an exit hole made by a larva of Cotesia marginiventris (Cresson), a wasp parasitoid, in a beet armyworm, Spodoptera exigua (Hbn.). Credits: Andrei Sourakov, USDA

Grant J. F. and M. Shepard. 1984. Laboratory biology of Meteorus autographae (Hymenoptera: Braconidae), an indigenous parasitoid of soybean looper (Lepidoptera: Noctuidae) larvae. Environ. Entomol. 13: 838-842.

Kunnalaca S. and A. J. Mueller. 1979. A laboratory study of Apanteles marginiventris, a parasitoid of green cloverworm. Environ. Entomol. 8: 365-368.

Mitchell, A., et al. (February 2000). Stage by stage comparison of parasitoids important in biocontrol of cabbage pests. USDA. http://www.usda.ufl.edu/biocontrol/guide.htm (March 2000).

Rajapaske, R. H. S., V. H. Waddill, and T. R. Ashley 1992. Effects of host age, parasitoid age and temperature on interspecific competition between Chelonus insularis Gresson, Cotesia marginiventris Gresson, and Microplitis manilae Ashmead. Insect. Sc. Applic., 13: 87-94. 